Published in final edited form as:

Curr Treat Options Infect Dis. 2016 December ; 8(4): 275-296. doi:10.1007/s40506-016-0086-4.

\title{
Treatment of Non-Tuberculous Mycobacterial Lung Disease
}

\author{
Julie V. Philley ${ }^{8}$, Mary Ann DeGroote ${ }^{4,5}$, Jennifer R. Honda ${ }^{1,3}$, Michael M. Chan ${ }^{6,7}$, Shannon \\ Kasperbauer $^{1,4}$, Nicholas D. Walter ${ }^{2,3}$, and Edward D. Chan ${ }^{1,2,3}$ \\ ${ }^{1}$ Department of Medicine and Academic Affairs, National Jewish Health, Denver, Colorado \\ ${ }^{2}$ Department of Medicine, Denver Veterans Affairs Medical Center, Denver, Colorado \\ ${ }^{3}$ Division of Pulmonary Sciences and Critical Care Medicine, University of Colorado Anschutz \\ Medical Campus, Aurora, Colorado \\ ${ }^{4}$ Division of Infectious Diseases, University of Colorado Anschutz Medical Campus, Aurora, \\ Colorado \\ ${ }^{5}$ Department of Microbiology, Immunology, and Pathology, Colorado State University, Fort Collins, \\ Colorado \\ ${ }^{6}$ University of Colorado School of Pharmacy, Aurora, Colorado \\ ${ }^{7}$ PharmcareUSA, Denver, Colorado \\ ${ }^{8}$ Division of Pulmonary and Critical Care Medicine, University of Texas Health Science Center, \\ University of Texas, Tyler, Texas
}

\section{Opinion Statement}

Treatment of non-tuberculous mycobacterial lung disease (NTM-LD) is challenging for several reasons including the relative resistance of NTM to currently available drugs and the difficulty in tolerating prolonged treatment with multiple drugs. Yet-to-be-done, large, multicenter, prospective randomized studies to establish the best regimens will also be arduous because multiple NTM species are known to cause human lung disease, differences in virulence and response to treatment between different species and strains within a species will make randomization more difficult, the need to distinguish relapse from a new infection, and the difficulty in adhering to the prescribed treatment due to intolerance, toxicity, and/or drug-drug interactions, often necessitating modification of therapeutic regimens. Furthermore, the out-of-state resident status of many patients seen at the relatively few centers that care for large number of NTM-LD patients pose logistical issues in monitoring response to treatment. Thus, current treatment regimens for NTMLD is largely based on small case series, retrospective analyses, and guidelines based on expert

Corresponding Author: Edward D. Chan, MD, D509, Neustadt Building, National Jewish Health, 1400 Jackson St, Denver, CO 80206 ChanE@ NJHealth.org, Phone: 303-398-1491, Fax: 303-270-2185.

Conflict of Interest

Dr. Julie V. Philley, Dr. Jennifer R. Honda, Dr. Michael M. Chan, Dr. Shannon Kasperbauer, Dr. Nicholas D. Walter, and Dr. Edward D. Chan declare that they have no conflict of interest. Dr. Mary Ann DeGroote is a co-PI for the pre-clinical evaluation of new therapeutic entities for NTM therapeutics with Crestonepharma Inc. This is an SBIR phase II grant. There is no overlap with antimicrobial agents described in this review.

Human and Animal Rights and Informed Consent

This article does not contain any studies with human or animal subjects performed by any of the authors. 
opinions. It has been nearly 10 years since the publication of a consensus guideline for the treatment of NTM-LD. This review is a summary of the available evidence on the treatment of the major NTM-LD until more definitive studies and guidelines become available.

\section{Keywords}

antibiotic; atypical mycobacteria; bronchiectasis; Mycobacterium abscessus complex; Mycobacterium avium complex; pulmonary disease

\section{Introduction}

Treatment of non-tuberculous mycobacterial lung disease (NTM-LD) is challenging because different NTM with varying virulence and drug susceptibility are known to be causative agents, the relative resistance of NTM to available antibiotics, requirement of multi-drug regimens for an extended period of time, frequent intolerance of the prescribed regimens, and the relatively high frequency of relapse and/or reinfection. Furthermore, expertrecommended antibiotic regimens are largely based on case series, small randomized studies, expert opinions, and anecdotal clinical experience. Herein, we review the current recommendations on treatment of NTM-LD based on the available evidence.

\section{The prevalence of NTM lung disease and potential sources of infections}

Well accepted among the clinical and scientific community is the rising rates of NTM-LD. Because of the chronicity of NTM-LD, the best measures of disease burden in a population are prevalence rates (1). In several countries including Australia, Canada, Germany, and Taiwan, the prevalence has increased by 1.5- to 6-fold over the past decade (2-5). In those $>65$ years-old in the United States, annual prevalence rates significantly increased from 20 to 47 cases/100,000 between 1997-2007 (an increase of 8\% per year) with Hawaii having the highest prevalence at 396 cases/100,000 (6). These numbers are likely underestimated because of a lack of mandatory reporting in the U.S.

There are potentially multiple reasons for the increased number of NTM-LD cases. One possibility is that the true number of cases is not increasing, but rather there are simply more cases being diagnosed due to greater utilization of chest CT scan (prompting sputum cultures in those with abnormalities), more reliance on more sensitive molecular diagnostic techniques, and greater awareness of NTM-LD by clinicians. However, increased exposure to NTM is also a factor as evinced by a study showing that skin test reactivity to purified protein derivative-B (a mixture of antigens from M. intracellulare) in the 1999-2000 period ( 7,400 subjects) was significantly greater than those tested in the 1971-1972 period ( 1,500 subjects) (17\% vs. $11 \%$, respectively) (7). Greater exposure may be related to enhanced biofilm development on polyvinyl chloride, steel, and polycarbonate surfaces where there is greater propensity for NTM biofilm formation compared to copper and glass surfaces (8) - and subsequent inhalation of fractured biofilm carried in fine water aerosols such as that seen with high efficiency showerheads, water misters, and hot tub bubble generators (9). In particular, NTM glycopeptidolipids have been linked to enhanced formation of biofilms (10). The production of extracellular polymeric substances (i.e., lipids, 
polysaccharides, and nucleic acids) in a three-dimensional matrix during the production of biofilms is a successful strategy used by NTM for survival in the environment (11). Compared to planktonic bacteria, those residing in biofilms exhibit 10- to 1000- fold greater resistance to antimicrobial agents and decontaminants $(8,12)$. The close proximity of NTM to each other in biofilms can also promote horizontal gene transfer (e.g., acquisition of drug resistance genes) and switch to slower growth rates that inhibit antibiotic efficiency. With increasing use of chlorination, it is possible that NTM - which are relatively resistant to chlorine except for $M$. scrofulaceum which has virtually disappeared with widespread chlorination - have increased in number because of less competition from chlorine-sensitive organisms. We have also speculated that climate change with global warming and natural disasters may also contribute to increasing infection and prevalence of NTM-LD (13).

While a link has been made to water and associated biofilms as potential sources of NTM lung infections (14), a recent study found that $M$. intracellulare - a member of the Mycobacterium avium complex (MAC) group of organisms and historically the most common cause of NTM-LD in the U.S. - was not commonly found in water biofilms; instead, M. chimaera (another MAC organism) was found in household water and biofilm samples (15). However, since traditional non-sequencing methods of NTM identification cannot speciate $M$. chimaera with any reliability, it is likely that a significant number of isolates previously classified as $M$. avium or $M$. intracellulare were in fact $M$. chimaera or another species under the MAC umbrella (16). Indeed, a report from Germany showed that $143 / 166(85 \%)$ of $M$. intracellulare isolates initially identified by $16 S r R N A$ gene-based methods were actually misidentified and were reclassified as $M$. chimaera after multilocus sequence analyses including a combination of $16 \mathrm{~S}$ rRNA gene and 16S-23S internal transcribed spacer (ITS) region sequencing (17). Furthermore, rpoB gene and 16S-23S ITS multilocus sequence analyses used to speciate 448 clinical MAC isolates in the U.S. revealed the dominant MAC to be M. avium (54\%), M. chimaera (28\%), and M. intracellulare (18\%) (18). Thus, since a significant number of previously identified $M$. intracellulare clinical isolates may actually be another MAC species, the infrequent finding of $M$. intracellulare in water biofilms should not diminish the importance of water and their associated biofilms as sources for NTM infections.

\section{Brief synopsis of NTM identification and diagnosis of NTM lung disease}

Determining the precise NTM species and even subspecies is critical since the antibiotic regimen and prognosis varies with the responsible NTM. Newer molecular techniques that allow more precise identification include line probe hybridization and PCR. For the most precise identification of NTM species and subspecies, sequencing of $h s p 65$ and $r p o B$ genes, as well as the 16S-23S ITS is recommended (19-23). Furthermore, the infrequent use of NTM genotyping in the clinical setting makes it difficult to ascertain whether recurrent disease is due to a relapse or a new infection acquired from the environment.

There is no reliable biomarker that distinguishes NTM colonization vs. NTM-LD. Thus, after identification of NTM from the respiratory tract, other clinical factors must be considered to determine if the isolated NTM is clinically relevant. A guideline published jointly by the American Thoracic Society/Infectious Diseases Society of America (ATS/ 
IDSA) espoused that, at a minimum, NTM-LD can be diagnosed when NTM-positive patients are symptomatic (e.g., cough, sputum, fatigue) and have radiographic features that are consistent with NTM-LD (e.g., nodules, bronchiectasis, tree-in-bud opacities, cavities). The NTM species can also help predict the clinical relevance; e.g., at one end of the spectrum, $M$. gordonae almost always is a laboratory contaminant and not a culprit organism whereas the presence of $M$. kansasii is a better predictor of NTM-LD (Table 1).

Even if one has established the presence of NTM-LD, patient factors such as age, co-morbid conditions, life expectancy, and goals of care (e.g., curative vs. symptom control) are important to consider since treatment for NTM-LD entails multiple antibiotics for an extended period of time (months to several years).

\section{Treatment of NTM-LD is based on small clinical studies and expert opinion}

Although treatment trials have been performed on patients with MAC-LD, participant numbers are generally small and often single-centered (24-28). Large, multi-center, prospective trials reminiscent of the studies performed on tuberculosis in Hong Kong, East Africa, U.S., and several other countries have not been done with NTM-LD. Challenges to conduct such studies include the relatively few NTM-LD patients at most centers, out-ofstate resident status of many patients at the few centers that care for large number of NTMLD patients, the difficulty of distinguishing relapse and reinfection with standard laboratory techniques, and the relatively high frequency of intolerance or toxicity to various antibiotic regimens in an older population, often necessitating temporary or permanent discontinuation of certain drugs or modification of regimens based on co-morbid conditions or drug-drug interactions. It has been nearly 10 years since the publication of the ATS/IDSA guidelines in the diagnosis and treatment of NTM-LD (29). Yet, Admejian et al recently showed that following the treatment guidelines is poor among clinicians who treat such patients (30). We discuss below the treatment of NTM-LD caused by MAC, $M$. kansasii, $M$. malmoense, $M$. xenopi, M. szulgai, M. simiae, and M. abscessus complex.

\section{Treatment for Mycobacterium avium complex (MAC)}

MAC has traditionally been comprised of several well-known species, including $M$. avium and $M$. intracellulare but more recently, also include a third group known as MAC "X", comprised of at least eight less common MAC species (15). In the U.S., standard laboratory testing is completed by partial sequencing and subsequent phylogenetic analysis of the $16 \mathrm{~S}$ $r R N A$ gene and thus the delineation of different strains of MAC is frequently unavailable. Currently, all species within MAC are similarly treated according to standard ATS/IDSA guidelines (29). But clearly, different "MAC strains" are associated with differential virulence (31); if future analyses find the virulence of MAC species significantly differs, distinguishing these MAC species may ultimately prove useful for prognosticating and perhaps guiding therapy $(32,33)$.

In contrast to treatment for tuberculosis, where in vitro susceptibility testing is a useful guide for effective in vivo response to antibiotics (29), the Clinical Laboratory Standards Institute and ATS/IDSA guidelines recommend testing MAC susceptibility only to clarithromycin (or 
azithromycin) (29). This recommendation is based on studies showing a relationship between clinical efficacy and minimum inhibitory concentration (MIC) for clarithromycin, but not for rifampicin, ethambutol or streptomycin (34-38). No studies have established superiority of one macrolide over another (28). Combined rifampin and ethambutol drug susceptibility testing has shown mutual lowering of the individual drug MIC, but the clinical importance of this in vitro synergy is controversial $(39,40)$. Susceptibility to amikacin ( $\leq 16$ $\mu \mathrm{g} / \mathrm{mL}$ for susceptible, $32 \mu \mathrm{g} / \mathrm{mL}$ for intermediate, and $\geq 64 \mu \mathrm{g} / \mathrm{mL}$ for resistant) may also help predict treatment success (41).

Two major radiographic phenotypes of NTM-LD are seen - nodular-bronchiectasis often involving the right middle lobe and lingula segment and the fibrocavitary form often involving the upper lobes - although patients may have features of both. For patients with nodular-bronchiectasis MAC-LD without cavitation, it is acceptable to treat with a macrolide, rifamycin, and ethambutol - the standard three-drug regimen - thrice weekly (Table 2) (29, 42-44). In a study that compared such dosing in 180 MAC-LD patients with nodular-bronchiectasis who completed $>12$ months of multidrug therapy, thrice weekly dosing was as good as daily dosing with combined treatment success rate of $84 \%$ (sputum conversion with no evidence of microbiologic relapse) (28). Interestingly, most of the recurrences (75\%) were due to new infections rather than a true relapse (25\%) (28). Overall, the standard three-drug regimen of a macrolide, rifamycin, and ethambutol gives a durable culture conversion rate of $\sim 60-80 \%(25,28,34,35,37,45)$.

For those with fibrocavitary disease, daily dosing rather than intermittent therapy with the standard three-drug regimen is recommended (Table 2) (43). With more severe disease, addition of an aminoglycoside during the first 2-3 months of therapy is recommended based on a study showing that addition of streptomycin to the standard three-drug regimen significantly improved the sputum conversion rates, albeit long-term outcome was not significantly better (27). There are small case series describing inhaled amikacin to treat MAC-LD with varying success (46-48). An ongoing multicenter study is recruiting patients to determine if inhaled liposomal amikacin helps for MAC-LD recalcitrant to the standard three-drug regimen (http://www.insmed.com/clinical-trials/).

Commensurate with the importance of a macrolide in the treatment of MAC-LD, the development of macrolide resistance in a MAC isolate is strongly associated with treatment failure and increased mortality (49). Factors associated with emergence of macrolide resistance include macrolide monotherapy and dual therapy with a macrolide and fluoroquinolone (49). Thus, avoiding these practices is a critical element in the management of patients with MAC-LD. However, once macrolide resistance develops, aggressive therapy, usually including use of an injectable aminoglycoside and possibly lung resection should be considered (49).

Second-line agents for MAC are generally reserved for those with disease recalcitrant to first-line treatment, intolerance or unacceptable adverse effects to one or more of the first line agents, and/or macrolide resistance. For patients intolerant to rifamycins, substitution with clofazimine is a viable option with prolonged sputum conversion rates for clofazimine, macrolide, and ethambutol or minocycline to be $\sim 65 \%$, similar to that seen with rifampin- 
based three-drug therapy $(25,45,50-53)$. Clofazimine synergizes with clarithromycin or amikacin against MAC $(50,52)$. The use of linezolid was assessed in a retrospective multicenter study across six NTM centers in over one hundred patients, $33 \%$ of whom had MAC-LD (54). Many of these patients had stable or improved disease on treatment but significant side effects occurred in about half. Bedaquiline, approved by the FDA in 2013 for the treatment of multidrug-resistant tuberculosis, appears to be well-tolerated in patients with refractory MAC-LD (55). A U.K. study compared 24 months of treatment for MAC-LD with either ciprofloxacin-ethambutol-rifamycin or macrolide-ethambutol-rifamycin and found similar and very low cure rates for both arms (23-24\%) but this may be due to the fact that two-thirds had cavitary disease (26), a sign of more severe disease. While this finding suggests that ciprofloxacin is equivalent to clarithromycin in efficacy, experts in North America and several other regions still consider clarithromycin or azithromycin the most important drug available for MAC. Moxifloxacin has been used with some success in MACLD patients who failed clarithromycin-based therapy (56). Thus, for refractory or resistant MAC-LD, there is little published data for treatment options apart from ATS/IDSA guidelines.

\section{Treatment for M. kansasii}

M. kansasii is one of the more common cause of NTM-LD in the Western hemisphere but is less common in Asia (58). M. kansasii is phylogenetically the most closely related NTM species to M. tuberculosis (59). It is considered the most virulent NTM and classically causes upper lobe fibrocavitary lung disease similar to tuberculosis. Historically, isolation of M. kansasii has been considered to almost always predict true NTM-LD. However, a recent review of 19 papers published over the course of 60 years found that 1,008 of 2,672 patients (38\%) evaluated after isolation of $M$. kansasii isolation did not meet clinical criteria for disease (60).

There are no randomized trials comparing treatment regimens for $M$. kansasii. Fortunately, $M$. kansasii is among the most antibiotic-responsive NTM species with a low rate of treatment failure or relapse $(<1 \%)$ among patients who completed the ATS/IDSA recommended treatment of daily isoniazid, rifampin, and ethambutol until cultures are negative for at least 12 months (Table 3) (29). Rifampin is the most important agent in this regimen as cure was uncommon in the pre-rifampin era (61).

M. kansasii is also typically susceptible to macrolides, fluoroquinolones, and the aminoglycosides but is intrinsically resistant to pyrazinamide. Susceptibility testing should be performed for rifampin and clarithromycin (62). Because isoniazid activity is lower for M. kansasii than for M. tuberculosis and macrolides have strong in vitro activity, an alternative regimen is replacing isoniazid with a macrolide. Indeed, two studies used a regimen of clarithromycin, rifampin and ethambutol daily or thrice weekly for at least 12 months of culture negativity while on treatment and identified no relapses after a long period of follow-up $(63,64)$. Patients receiving shorter courses (9 to 12 months) with different regimens have experienced unacceptable rates of relapse $(6-10 \%)(65,66)$. Earlier regimens also included streptomycin in the first three months $(61,67)$ but since high cure rates are typically achieved with oral regimens, aminoglycosides are rarely necessary. For rifampin- 
resistant $M$. kansasii, ATS/IDSA recommends a combination of clarithromycin, moxifloxacin, and a third agent with in vitro susceptibility such as ethambutol or sulfamethoxazole (29).

\section{Treatment for M. malmoense}

M. malmoense is an uncommon pathogen in the U.S., but is a more common cause of NTMLD in Europe. It grows more slowly than MAC in liquid media and historically, it is a difficult species to treat. Similar to MAC, many clinicians cannot correlate in vitro susceptibilities with an in vivo response. A prospective study of 106 patients with $M$. malmoense-LD was performed over a 5-year period by the British Thoracic Society (BTS) (68). The results of two years of treatment with rifampin plus ethambutol were equivalent to rifampin, ethambutol plus isoniazid, although only $53 \%$ of patients were alive at 5 years and 44 of the original 106 patients (42\%) were cured of the infection (68). In a follow-up study, the BTS randomly assigned 167 patients with M. malmoense-LD to clarithromycin, rifampin, and ethambutol, or ciprofloxacin, rifampin, and ethambutol. Overall response rates were low, but the group receiving clarithromycin had slightly better clinical response and lower mortality (26). There have been several other retrospective studies with varying success to rifampicin and ethambutol with or without a macrolide $(45,69,70)$. Overall, the optimum antibiotic regimen to treat $M$. malmoense remains unknown but based on available evidence, standard MAC therapy is a reasonable place to start (Table 4).

\section{Treatment of $M$. szulgai}

M. szulgai, an organism closely related to $M$. malmoense (71), is one of a few NTM that possess the ESAT- 6 and CFP-10 - small secretory proteins produced by M. tuberculosis but only by a few NTM - indicating that it may contain virulence genes similar to $M$. tuberculosis (72). Consistent with this hypothesis is that isolation of M. szulgai from a patient generally indicates actual disease (73). M. szulgai is known to cause chronic lung disease and skin and soft-tissue infections. Treatment regimens that consist of clarithromycin, rifampin, and ethambutol ( \pm ciprofloxacin) have been used successfully (Table 5) $(73,74)$.

\section{Treatment of M. xenopi}

M. xenopi is named for its isolation from the toad Xenopus laevis (75). It is mainly isolated from water sources (29) and clinically more relevant in certain parts of the world including Europe (76-78).

$M$. xenopi is often recalcitrant to treatment, with correspondingly lower sputum conversion rates, reduced long-term cure rates, and associated with higher mortality $(24,26,45,78,79)$. There is real resistance to typical anti-tuberculosis drugs such as rifampin, isoniazid, and ethambutol (80); however, the rifabutin $\mathrm{MIC}_{50}$ for a small number of strains tested was $<0.5$ (81). In time-kill kinetic studies, moxifloxacin and clarithromycin are equally effective (82). In vitro activity with ciprofloxacin and amikacin was limited (83), whereas no in vitro synergy between rifampin and ethambutol was seen (39). Andrejak and co-workers 
performed a comprehensive study of antimicrobials using drugs in vitro, sera of treated mice to assess antimicrobial activities ex vivo, and in vivo murine models to test drug activities (84). They found that in vitro, two-drug combinations of ethambutol plus either rifamycin or moxifloxacin, and of clarithromycin plus moxifloxacin showed the best bactericidal activities; ex vivo, a three-drug combination of ethambutol plus a rifamycin and either clarithromycin or moxifloxacin was best (84). Interestingly, for the in vivo studies, amikacin-containing regimen had the greatest bactericidal activity with no difference in regimens containing clarithromycin or moxifloxacin (84). Based on a few trials, isoniazid is not effective and may in fact be associated with worse outcomes $(24,85)$. Short of more robust studies, the most efficacious drugs are the rifamycins, macrolides, and the fluoroquinolones $(26,29,45,78,86)$. Thus, based on available evidence, it is recommended that $M$. xenopi-LD be treated with a combination of a macrolide, rifamycin, ethambutol $\pm \mathrm{a}$ fluoroquinolone (Table 6) $(26,45)$.

\section{Treatment of M. simiae}

M. simiae is isolated from water sources in the environment $(29,71)$ and is capable of, but rarely causes disease; i.e., a positive culture is a low predictor of having actual NTM-LD $(87,88)$. When implicated in pulmonary disease, its clinical presentation has similarities to that seen with MAC-LD (89). This organism is resistant to many of the standard tuberculosis drugs such as isoniazid, rifamycin, ethambutol, and para-aminosalicylic acid $(81,90)$. In one report, 27 of 86 isolates (31\%) were susceptible to streptomycin (91). Agents that have in vitro activity include ofloxacin, amikacin, clarithromycin, ethionamide, cycloserine, and clofazimine (92). Like M. xenopi, no in vitro synergy was seen between rifampin and ethambutol (39); however, synergy could be demonstrated between amikacin and clofazimine (52). Jeong et al recently reported the first confirmed South Korean patient with M. simiae-LD who, despite receiving 12 month treatment with azithromycin, rifampin, ethambutol, and moxifloxacin, failed to achieve culture conversion (93). ATS/IDSA guidelines primarily suggest a clarithromycin-based, multiple drug regimen, citing that drugs such as moxifloxacin, sulfamethoxazole/trimethoprim, or linezolid have activity against M. simiae (Table 7) (29). For cavitary disease, extrapolation for MAC treatment suggests amikacin for a period of time could be helpful. Overall, the results of therapy are often disappointing and treatment for $M$. simiae remains problematic (57).

\section{Treatment for M. abscessus complex and M. chelonae}

Among the rapidly growing mycobacteria (RGM) - defined historically as observable growth from a subculture on solid medium in $<7$ days - those belonging to the $M$. abscessus complex are the most clinically relevant to humans. Whole genome sequencing support categorizing $M$. abscessus complex into three distinct subspecies: $M$. abscessus sensu stricto, $M$. bolletii, and $M$. massiliense (94). In the clinical laboratory, distinguishing these three $M$. abscessus complex subspecies can be difficult and often requires sequencing of $h s p 65, r p o B$, $\sec A$, erythromycin ribosomal methylase 41 (erm41), and/or $16 S$-23S rRNA ITS.

Pang and co-workers performed in vitro susceptibility testing of 40 international reference RGM to 20 antimicrobial agents and found amikacin, tigecycline, and linezolid had potent 
activities and that the fluoroquinolones, cefoxitin, and meropenem had good activities (95). Although the Clinical and Laboratory Standards Institute recommends drug susceptibility testing to 10 antimicrobial agents (amikacin, cefoxitin, clarithromycin, ciprofloxacin, doxycycline or minocycline, imipenem, linezolid, moxifloxacin, trimethoprimsulfamothoxazole, and tobramycin) for $M$. abscessus complex isolates $(96,97)$ and recommended by some experts $(94,98)$, others cite insufficient evidence that in vitro susceptibility correspond with in vivo response with the exception of the macrolides (99). The method of drug susceptibility testing (e.g., disc diffusion vs. broth dilution methods with the latter method preferred) may account for differences in drug susceptibility and hence, differences in reliability of the results in predicting outcome (96). One study from South Korea noted sputum conversion and maintenance of negative sputum cultures for more than 12 months were significantly lower in patients whose isolates were resistant to clarithromycin $(2 / 12,17 \%)$ compared with those whose isolates were susceptible or intermediate to clarithromycin $(21 / 33,64 \%)(100)$.

A distinguishing feature of $M$. abscessus sensu stricto and $M$. bolletii from M. massiliense is that the first two RGM have poor treatment outcomes. The reason for this is the presence of the functional erm 41 gene in both $M$. abscessus sensu stricto and M. bolletii, which, upon exposure to macrolides, modifies the binding site for macrolides and induces resistance (101). Clarithromycin may have greater propensity to induce greater erm 41 expression resulting in greater macrolide resistance than azithromycin in $M$. abscessus sensu stricto infection (102) although others have not found a difference in the two macrolides to induce such resistance (103). Additionally, $M$. abscessus sensu stricto possesses other enzymes and efflux pumps that may confer in vivo antibiotic resistance (36).

Koh et al summarized the four studies (three from South Korea and one from Denver, Colorado) examining the treatment outcome for $M$. abscessus-LD (94). In the three studies that did not distinguish the subspecies of $M$. abscessus complex, the sputum conversion rate without evidence of relapse was 50-70\%. In contrast, in the one study from South Korea where $M$. massiliense was distinguished from $M$. abscessus sensu stricto, the sputum conversion rate was significantly more favorable for $M$. massiliense (88\%) than for $M$. abscessus sensu stricto (25\%) (104). This finding indicates that the presence of the erm 41 gene may be the reason for the generally poor response of $M$. abscessus sensu stricto to medical therapy as oppose to the more favorable outcomes in the treatment of lung disease due to $M$. massiliense (104-106). Thus, this is a good example where distinguishing the subspecies has important prognostic implications for patients.

The only oral drugs with reliable activity against $M$. abscessus complex organisms are the macrolides and clofazimine, although others that have been used in treatment include ciprofloxacin, moxifloxacin, linezolid, or doxycycline (107). Similar to that for MAC, clofazimine was found to synergize with clarithromycin or amikacin against $M$. abscessus (50). Parenteral drugs used in the treatment of $M$. abscessus complex include cefoxitin, imipenem, tigecycline, and amikacin.

Current guidelines recommend an initial intensive phase of daily clarithromycin or azithromycin and two parenteral drugs for 2-4 months (e.g., amikacin thrice weekly plus 
daily imipenem or cefoxitin in divided doses) followed by macrolide therapy with at least one other oral agent (fluoroquinolone, linezolid, clofazimine) or inhaled amikacin $(45,108$, 109). If the isolate is identified as $M$. abscessus sensu stricto or $M$. bolletii, then the macrolide should not be used and inhaled amikacin plus clofazimine should be considered in the continuation phase (Table 8). The total duration of therapy is based on culture conversion, typically treating for $\geq 12$ months of negative sputum cultures. On the other hand, if the goal is symptom control and not intent to cure, then the continuation phase can be shortened to a few months.

In contrast to $M$. abscessus sensu stricto, $M$. chelonae - a much less common cause of lung disease - does not have an active erm 41 gene and thus should not have inducible macrolide resistance.

\section{Role of resectional lung surgery}

Surgical resection can play an important adjunctive role in the management of NTM-LD $(29,110)$. However, there is a paucity of robust evidence to guide the calculation of risks and benefits of selecting NTM-LD patients for lung resection. A number of single-center, retrospective case series have reported long-term microbiological success after lung resection for NTM-LD (111-119). Case series of M. abscessus patients have suggested improved outcomes with surgical resection relative to antibiotic treatment alone $(100,108$, 120). Nonetheless, several caveats are critical in interpretation of these data. First, these reports come from centers with extensive experience with surgical techniques specific to infectious lung disease. Results should not be extrapolated to centers with less experience in these highly specialized techniques. Second, patients seen in these centers are highly selected and may not be representative of NTM patients generally.

Expert opinion emphasizes consideration of surgical resection under the following circumstances: (i) for pathogens that are less amenable to medical therapy such as $M$. abscessus or macrolide-resistant MAC organisms, (ii) for severely involved but localized disease (e.g., focal bronchiectasis or cavitation), and/or (iii) for patients who have responded poorly to initial medical treatment and for life-threatening complications such as hemoptysis $(29,110)$. Patients are typically treated with intensive antibiotic regimens for $2-3$ months prior to surgery to maximally reduce bacterial burden (110). ATS/IDSA guidelines conclude that - in light of the lack of widely-accepted criteria for patient selection and the high potential morbidity - decision-making regarding surgical resection should optimally be made in conjunction with experienced NTM treatment centers (29).

\section{Adjunctive treatment}

In addition to antimicrobial therapy, avoidance of potential sources of exposure (e.g., aerosolized water, soil, and biofilms) is necessary to prevent re-infection. In patients who are on inhaled corticosteroids, a trial to limit their use may potentially help with treatment as inhaled corticosteroids have been shown to be a risk factor for acquiring NTM-LD and by inference, presumably may hinder response to therapy (121). Moreover, measures to improve airway clearance in the bronchiectatic airways are essential adjunct to drug 
treatment - e.g., airway clearance devices $\left(\right.$ Acapella $^{\circledR}$, Aerobika $^{\circledR}$, TheraVest $\left.{ }^{\circledR}\right)$, agents to enhance expectoration of mucous (e.g., inhaled hypertonic saline or mannitol), and optimization of nutrition. Other measures to maximize favorable treatment outcome are listed in Table 9.

\section{Traditional and more novel predictors of treatment outcome}

Traditional factors that may contribute to suboptimal outcome include innate and acquired resistance including to the endogenous antimicrobial peptide cathelicidin $(36,127)$, underdosing of antimicrobials (122), the presence of other pathogens in the respiratory tract (NTM or non-NTM bacteria or fungi), and newly-acquired NTM infections during treatment or after completion.

In 72 Japanese patients with MAC-LD on triple drug regimen, in whom $51 \%$ experienced treatment success - defined as sputum conversion without relapse - low soil exposure (defined as $\leq 2 \mathrm{hrs}$ of soil-related activities per week) was associated with significantly greater sputum conversion, lower rates of relapse, and higher treatment success rates than those with high soil exposure ( $>2$ hours per week) (123). This finding is consistent with the long-standing observation with now experimental proof that a substantial number of recurrences are due to a new infection rather than a true relapse (28).

While treatment outcome is most often discussed in the context of the antibiotic regimen used and perhaps drug susceptibility, some investigators have examined the association between outcome and genotype of the organisms. Kikuchi and co-workers categorized patients with $M$. avium- $L D$ as having a therapeutic responsiveness (defined as microbiologic and radiologic improvement) or unresponsiveness and then retrospectively determined whether there was an association between the M. avium genotype of the variable number tandem repeats (VNTR) at 16 minisatellite loci and responsiveness to therapy (128). Performing principal component analysis of the raw VNTR data, they were able to identify genetic features that were associated with therapeutic response to clarithromycin-containing regimen. Subsequently, they constructed a multivariate model to predict therapeutic responsiveness using VNTR data from only four minisatellite loci (128). This study would lend credence to the notion that different strains of NTM - even within the same species may have differential virulence. In contrast, Kim S-Y et al found no association between the clinical characteristics, drug susceptibility, disease progression and $M$. intracellulare cluster based on VNTR genotyping (129).

\section{Conclusions and Future Developments}

In conclusion, we summarized the treatment of NTM-LD based on available data with the caveat that many of the recommendations are based on clinical experience, small clinical studies, and expert opinions. Systematic, multi-center studies are needed to provide more robust evidence-based recommendations for treatment and outcome analysis of NTM-LD.

\section{References}

Papers of particular interest, published recently, have been highlighted as: 
- Of importance

•• Of major importance

1. Prevots DR, Marras TK. Epidemiology of human pulmonary infection with nontuberculous mycobacteria: a review. Clin Chest Med. 2015; 36:13. [PubMed: 25676516]

2. Lai CC, Tan CK, Chou CH, Hsu HL, Liao CH, Huang YT, et al. Increasing incidence of nontuberculous mycobacteria, Taiwan, 2000-2008. Emerg Infect Dis. 2010; 16:294. [PubMed: 20113563]

3. Marras TK, Mendelson D, Marchand-Austin A, May K, Jamieson FB. Pulmonary nontuberculous mycobacterial disease, Ontario, Canada, 1998-2010. Emerg Infect Dis. 2013; 19:1889. [PubMed: 24210012]

4. Ringshausen FC, Wagner D, de Roux A, Diel R, Hohmann D, Hickstein L, et al. Prevalence of Nontuberculous Mycobacterial Pulmonary Disease, Germany, 2009-2014. Emerg Infect Dis. 2016; 22:1102. [PubMed: 27191473]

5. Thomson RM, NTM working group at Queensland TB Control Centre and Queensland Mycobacterial Reference Laboratory. Changing epidemiology of pulmonary nontuberculous mycobacteria infections. Emerg Infect Dis. 2010; 16:1576. [PubMed: 20875283]

6. Adjemian J, Olivier KN, Seitz AE, Holland SM, Prevots DR. Prevalence of nontuberculous mycobacterial lung disease in U.S. Medicare beneficiaries. Am J Respir Crit Care Med. 2012; 185:881. [PubMed: 22312016]

7. Khan K, Wang J, Marras TK. Nontuberculous mycobacterial sensitization in the United States: National trends over three decades. Am J Respir Crit Care Dis. 2007; 176:306.

8. Williams MM, Yakrus MA, Arduino MJ, Cooksey RC, Crane CB, Banerjee SN, et al. Structural analysis of biofilm formation by rapidly and slowly growing nontuberculous mycobacteria. Appl Environ Microbiol. 2009; 75:2091. [PubMed: 19201956]

9. Mullis SN, Falkinham JO 3rd. Adherence and biofilm formation of Mycobacterium avium, Mycobacterium intracellulare and Mycobacterium abscessus to household plumbing materials. J Appl Microbiol. 2013; 115:908. [PubMed: 23742161]

10. Recht J, Kolter R. Glycopeptidolipid acetylation affects sliding motility and biofilm formation in Mycobacterium smegmatis. J Bacteriol. 2001; 183:5718. [PubMed: 11544235]

11. Sousa S, Bandeira M, Carvalho PA, Duarte A, Jordao L. Nontuberculous mycobacteria pathogenesis and biofilm assembly. Int J Mycobacteriol. 2015; 4:36.

12. Simões M. Antimicrobial strategies effective against infectious bacterial biofilms. Curr Med Chem. 2011; 18:2129. [PubMed: 21517762]

13. Honda JR, Bernhard JN, Chan ED. Natural disasters and nontuberculous mycobacteria: A recipe for increased disease? Chest. 2015; 147:304. [PubMed: 25644904]

14. Falkinham JO 3rd, Iseman MD, de Haas P, van Soolingen D. Mycobacterium avium in a shower linked to pulmonary disease. J Water Health. 2008; 6:209. [PubMed: 18209283]

15. Wallace RJ Jr, Iakhiaeva E, Williams MD, Brown-Elliott BA, Vasireddy S, Vasireddy R, et al. Absence of Mycobacterium intracellulare and presence of Mycobacterium chimaera in household water and biofilm samples of patients in the United States with Mycobacterium avium complex respiratory disease. J Clin Microbiol. 2013; 51:1747. [PubMed: 23536397]

16. Tortoli E, Rindi L, Garcia MJ, Chiaradonna P, Dei R, Garzelli C, et al. Proposal to elevate the genetic variant MAC-A, included in the Mycobacterium avium complex, to species rank as Mycobacterium chimaera sp. nov. Int J Syst Evol Microbiol. 2004; 54(Pt 4):1277. [PubMed: 15280303]

17. Schweickert B, Goldenberg O, Richter E, Göbel UB, Petrich A, Buchholz P, et al. Occurrence and clinical relevance of Mycobacterium chimaera sp. nov., Germany. Emerg Infect Dis. 2008; 14:1443. [PubMed: 18760016]

18. Boyle DP, Zembower TR, Reddy S, Qi C. Comparison of clinical features, virulence, and relapse among Mycobacterium avium complex species. Am J Respir Crit Care Med. 2015; 191:1310. [PubMed: 25835090] 
19. Frothingham R, Wilson KH. Sequence-based differentiation of strains in the Mycobacterium avium complex. J Bacteriol. 1993; 175:2818. [PubMed: 8491701]

20. Ben Salah I, Adékambi T, Raoult D, Drancourt M. rpoB sequence-based identification of Mycobacterium avium complex species. Microbiology. 2008; 154:3715. [PubMed: 19047739]

21. Zelazny AM, Root JM, Shea YR, Colombo RE, Shamputa IC, Stock F, et al. Cohort study of molecular identification and typing of Mycobacterium abscessus, Mycobacterium massiliense, and Mycobacterium bolletii. J Clin Microbiol. 2009; 47:1985. [PubMed: 19420162]

22. Macheras E, Roux AL, Bastian S, Leão SC, Palaci M, Sivadon-Tardy V, et al. Multilocus sequence analysis and rpoB sequencing of Mycobacterium abscessus (sensu lato) strains. J Clin Microbiol. 2011; 49:491. [PubMed: 21106786]

23. Jang MA, Koh WJ, Huh HJ, Kim SY, Jeon K, Ki CS, et al. Distribution of nontuberculous mycobacteria by multigene sequence-based typing and clinical significance of isolated strains. $\mathbf{J}$ Clin Microbiol. 2014; 52:1207. [PubMed: 24501029]

24. Research Committee of the British Thoracic Society. First randomised trial for pulmonary disease caused by $M$. avium intracellulare, $M$. malmoense and $M$. xenopi in HIV negative patients: rifampicin, ethambutol and isoniazid versus rifampicin and ethambutol. Thorax. 2001; 56:167. [PubMed: 11182006]

25. Field SK, Cowie RL. Treatment of Mycobacterium avium-intracellulare complex lung disease with a macrolide, ethambutol, and clofazimine. Chest. 2003; 124:1482. [PubMed: 14555583]

26. Jenkins PA, Campbell IA, Banks J, Gelder CM, Prescott RJ, Smith AP. Clarithromycin vs ciprofloxacin as adjuncts to rifampicin and ethambutol in treating opportunist mycobacterial lung diseases and an assessment of Mycobacterium vaccae immunotherapy. Thorax. 2008; 63:627. [PubMed: 18250184]

27. Kobashi Y, Matsushima T, Oka M. A double-blind randomized study of aminoglycoside infusion with combined therapy for pulmonary Mycobacterium avium complex disease. Respir Med. 2007; 101:130. [PubMed: 16750618]

28. Wallace RJ Jr, Brown-Elliott BA, McNulty S, Philley JV, Killingley J, Wilson RW, et al. Macrolide/Azalide therapy for nodular/bronchiectatic mycobacterium avium complex lung disease. Chest. 2014; 146:276. [PubMed: 24457542]

29. Griffith DE, Aksamit T, Brown-Elliott BA, Catanzaro A, Daley C, Gordin F, et al. An official ATS/ IDSA statement: diagnosis, treatment, and prevention of nontuberculous mycobacterial diseases. Am J Respir Crit Care Med. 2007; 175:367. [PubMed: 17277290]

30. Adjemian J, Prevots DR, Gallagher J, Heap K, Gupta R, Griffith D. Lack of adherence to evidencebased treatment guidelines for nontuberculous mycobacterial lung disease. Ann Am Thorac Soc. 2014; 11:9. [PubMed: 24236749]

31. Tateishi Y, Hirayama Y, Ozeki Y, Nishiuchi Y, Yoshimura M, Kang J, et al. Virulence of Mycobacterium avium complex strains isolated from immunocompetent patients. Microb Pathog. 2009; 46:6. [PubMed: 19013228]

32. Stout JE, Hopkins GW, McDonald JR, Quinn A, Hamilton CD, Reller LB, et al. Association between 16S-23S internal transcribed spacer sequence groups of Mycobacterium avium complex and pulmonary disease. J Clin Microbiol. 2008; 46

33. Han XY, Tarrand JJ, Infante R, Jacobson KL, Truong M. Clinical significance and epidemiologic analyses of Mycobacterium avium and Mycobacterium intracellulare among patients without AIDS. J Clin Microbiol. 2005; 43:4407. [PubMed: 16145084]

34. Kobashi Y, Abe M, Mouri K, Obase Y, Kato S, Oka M. Relationship between clinical efficacy for pulmonary MAC and drug-sensitivity test for isolated MAC in a recent 6-year period. J Infect Chemother. 2012; 18:436. [PubMed: 22205543]

35. Kobashi Y, Yoshida K, Miyashita N, Niki Y, Oka M. Relationship between clinical efficacy of treatment of pulmonary Mycobacterium avium complex disease and drug-sensitivity testing of Mycobacterium avium complex isolates. J Infect Chemother. 2006; 12:195. [PubMed: 16944258]

36. van Ingen J, Boeree MJ, van Soolingen D, Mouton JW. Resistance mechanisms and drug susceptibility testing of nontuberculous mycobacteria. Drug Resist Updat. 2012; 15:149. [PubMed: 22525524] 
37. Wallace RJ Jr, Brown BA, Griffith DE, Girard WM, Murphy DT. Clarithromycin regimens for pulmonary Mycobacterium avium complex. The first 50 patients. Am J Respir Crit Care Med. 1996; 153:1766. [PubMed: 8665032]

38. Tanaka E, Kimoto T, Tsuyuguchi K, Watanabe I, Matsumoto H, Niimi A, et al. Effect of clarithromycin regimen for Mycobacterium avium complex pulmonary disease. Am J Respir Crit Care Med. 1999; 160:866. [PubMed: 10471610]

39. van Ingen J, Hoefsloot W, Mouton JW, Boeree MJ, van Soolingen D. Synergistic activity of rifampicin and ethambutol against slow-growing nontuberculous mycobacteria is currently of questionable clinical significance. Int J Antimicrob Agents. 2013; 42:80. [PubMed: 23664674]

40. Hoffner SE, Heurlin N, Petrini B, Svenson SB, Källenius G. Mycobacterium avium complex develop resistance to synergistically active drug combinations during infection. Eur Respir J. 1994; 7:247. [PubMed: 8162976]

41. Brown-Elliott BA, Iakhiaeva E, Griffith DE, Woods GL, Stout JE, Wolfe CR, et al. In vitro activity of amikacin against isolates of Mycobacterium avium complex with proposed MIC breakpoints and finding of a 16S rRNA gene mutation in treated isolates. J Clin Microbiol. 2013; 51:3389. [PubMed: 23946523]

42. Griffith DE, Brown BA, Murphy DT, Girard WM, Couch L, Wallace RJ Jr. Initial (6-month) results of three-times-weekly azithromycin in treatment regimens for Mycobacterium avium complex lung disease in human immunodeficiency virus-negative patients. J Infect Dis. 1998; 178:121. [PubMed: 9652431]

43. Lam PK, Griffith DE, Aksamit TR, Ruoss SJ, Garay SM, Daley CL, et al. Factors related to response to intermittent treatment of Mycobacterium avium complex lung disease. Am J Respir Crit Care Med. 2006; 173:1283. [PubMed: 16514112]

44. Griffith DE, Brown BA, Cegielski P, Murphy DT, Wallace RJ Jr. Early results (at 6 months) with intermittent clarithromycin-including regimens for lung disease due to Mycobacterium avium complex. Clin Infect Dis. 2000; 30:288. [PubMed: 10671330]

45. van Ingen J, Ferro BE, Hoefsloot W, Boeree MJ, van Soolingen D. Drug treatment of pulmonary nontuberculous mycobacterial disease in HIV-negative patients: the evidence. Expert Rev Anti Infect Ther. 2013; 11:1065. [PubMed: 24124798]

46. Olivier KN, Shaw PA, Glaser TS, Bhattacharyya D, Fleshner M, Brewer CC, et al. Inhaled amikacin for treatment of refractory pulmonary nontuberculous mycobacterial disease. Ann Am Thorac Soc. 2014; 11:30. [PubMed: 24460437]

47. Davis KK, Kao PN, Jacobs SS, Ruoss SJ. Aerosolized amikacin for treatment of pulmonary Mycobacterium avium infections: an observational case series. BMC Pulm Med. 2007; 7:2. [PubMed: 17319962]

48. Safdar A. Aerosolized amikacin in patients with difficult-to-treat pulmonary nontuberculous mycobacteriosis. Eur J Clin Microbiol Infect Dis. 2012; 31:1883. [PubMed: 22198679]

49. Griffith DE, Brown-Elliott BA, Langsjoen B, Zhang Y, Pan X, Girard W, et al. Clinical and molecular analysis of macrolide resistance in Mycobacterium avium complex lung disease. Am J Respir Crit Care Med. 2006; 174:928. [PubMed: 16858014]

50. Ferro BE, Meletiadis J, Wattenberg M, de Jong A, van Soolingen D, Mouton JW, et al. Clofazimine prevents the regrowth of Mycobacterium abscessus and Mycobacterium avium type strains exposed to amikacin and clarithromycin. Antimicrob Agents Chemother. 2015; 60:1097. [PubMed: 26643335]

51. Jarand J, Davis JP, Cowie RL, Field SK, Fisher DA. Long-term follow-up of Mycobacterium avium complex lung disease in patients treated with regimens Including clofazimine and/or rifampin. Chest. 2016; 149:1285. [PubMed: 26513209]

52. van Ingen J, Totten SE, Helstrom NK, Heifets LB, Boeree MJ, Daley CL. In vitro synergy between clofazimine and amikacin in treatment of nontuberculous mycobacterial disease. Antimicrob Agents Chemother. 2012; 56:6324. [PubMed: 23027189]

53. Roussel G, Igual J. Clarithromycin with minocycline and clofazimine for Mycobacterium avium intracellulare complex lung disease in patients without the acquired immune deficiency syndrome. GETIM. Groupe d'Etude et de Traitement des Infections à Mycobactéries. Int J Tuberc Lung Dis. 1998; 2:462. [PubMed: 9626603] 
54. Winthrop KL, Ku JH, Marras TK, Griffith DE, Daley CL, Olivier KN, et al. The tolerability of linezolid in the treatment of nontuberculous mycobacterial disease. Eur Respir J. 2015; 45:1177. [PubMed: 25614169]

55. Philley JV, Wallace RJ Jr, Benwill JL, Taskar V, Brown-Elliott BA, Thakkar F, et al. Preliminary results of bedaquiline as salvage therapy for patients with nontuberculous mycobacterial lung disease. Chest. 2015; 148:499. [PubMed: 25675393]

56. Koh WJ, Hong G, Kim SY, Jeong BH, Park HY, Jeon K, et al. Treatment of refractory Mycobacterium avium complex lung disease with a moxifloxacin-containing regimen. Antimicrob Agents Chemother. 2013; 57:2281. [PubMed: 23478956]

57. Philley JV, Griffith DE. Treatment of slowly growing mycobacteria. Clin Chest Med. 2015; 36:79. [PubMed: 25676521]

58. Bittner MJ, Horowitz EA, Safranek TJ, Preheim LC. Emergence of Mycobacterium kansasii as the leading mycobacterial pathogen isolated over a 20-year period at a midwestern Veterans Affairs hospital. Clin Infect Dis. 1996; 22:1109. [PubMed: 8783725]

59. Wang J, McIntosh F, Radomski N, Dewar K, Simeone R, Enninga J, et al. Insights on the emergence of Mycobacterium tuberculosis from the analysis of Mycobacterium kansasii. Genome Biol Evolution. 2015; 7:856.

60. Moon SM, Park HY, Jeon K, Kim S-Y, Chung MJ, Huh HJ, et al. Clinical significance of Mycobacterium kansasii isolates from respiratory specimens. PLoS ONE. 2015; 10:e0139621. [PubMed: 26431540]

61. Santin M, Dorca J, Alcaide F, Gonzalez L, Casas S, Lopez M, et al. Long-term relapses after 12month treatment for Mycobacterium kansasii lung disease. Eur Respir J. 2009; 33:148. [PubMed: 19118226]

62. Woods, GL., Brown-Elliott, BA., Conville, PS., Desmond, EP., Hall, GS., Lin, G., et al. Susceptibility testing of mycobacteria, nocardiae, and other aerobic actinomtcetes: Approved Standard. Second. Institute CaLS. , editor. Wayne, Pennsylvania: 2011. CSLI document M24-A2

63. Shitrit D, Baum GL, Priess R, Lavy A, Shitrit AB, Raz M, et al. Pulmonary Mycobacterium kansasii infection in Israel, 1999-2004: Clinical features, drug susceptibility, and outcome. Chest. 2006; 129:771. [PubMed: 16537880]

64. Griffith DE, Brown-Elliott BA, Wallace RJ Jr. Thrice-weekly clarithromycin-containing regimen for treatment of Mycobacterium kansasii lung disease: results of a preliminary study. Clin Infect Dis. 2003; 37:1178. [PubMed: 14557961]

65. Kaustova J, Chmelik M, Ettlova D, Hudec V, Lazarova H, Richtrova S. Disease due to Mycobacterium kansasii in the Czech Republic: 1984-89. Tuber Lung Dis. 1995; 76:205. [PubMed: 7548902]

66. Mycobacterium kansasii pulmonary infection: a prospective study of the results of nine months of treatment with rifampicin and ethambutol. Research Committee, British Thoracic Society. Thorax. 1994; 49:442. [PubMed: 8016763]

67. Ahn CH, Lowell JR, Ahn SS, Ahn SI, Hurst GA. Short-course chemotherapy for pulmonary disease caused by Mycobacterium kansasii. Am Rev Respir Dis. 1983; 128:1048. [PubMed: 6650978]

68. Research Committee of the British Thoracic Society. Pulmonary disease caused by M. malmoense in HIV negative patients: 5-yr follow-up of patients receiving standardised treatment. Eur Respir J. 2003; 21:478. [PubMed: 12662005]

69. Murray MP, Laurenson IF, Hill AT. Outcomes of a standardized triple-drug regimen for the treatment of nontuberculous mycobacterial pulmonary infection. Clin Infect Dis. 2008; 47:222. [PubMed: 18532890]

70. Hoefsloot W, van Ingen J, de Lange WC, Dekhuijzen PN, Boeree MJ, van Soolingen D. Clinical relevance of Mycobacterium malmoense isolation in The Netherlands. Eur Respir J. 2009; 34:926. [PubMed: 19386689]

71. Wayne LG, Sramek HA. Agents of newly recognized or infrequently encountered mycobacterial diseases. Clin Microbiol Rev. 1992; 5:1. [PubMed: 1735092] 
72. van Ingen J, de Zwaan R, Dekhuijzen R, Boeree M, van Soolingen D. Region of difference 1 in nontuberculous mycobacterium species adds a phylogenetic and taxonomical character. $\mathrm{J}$ Bacteriol. 2009; 191:5865. [PubMed: 19617365]

73. van Ingen J, Boeree MJ, de Lange WC, de Haas PE, Dekhuijzen PN, van Soolingen D. Clinical relevance of Mycobacterium szulgai in The Netherlands. Clin Infect Dis. 2008; 46:1200. [PubMed: 18444856]

74. van Ingen J, Boeree M, Janssen M, Ullmann E, de Lange W, de Haas P, et al. Pulmonary Mycobacterium szulgai infection and treatment in a patient receiving anti-tumor necrosis factor therapy. Nat Clin Pract Rheumatol. 2007; 3:414. [PubMed: 17599076]

75. Marks J, Schwabacher H. Infection due to Mycobacterium xenopi. Br Med J. 1965; 1:32. [PubMed: 14213101]

76. Hoefsloot W, van Ingen J, Andrejak C, Angeby K, Bauriaud R, Bemer P, et al. Nontuberculous Mycobacteria Network European Trials Group. The geographic diversity of nontuberculous mycobacteria isolated from pulmonary samples: an NTM-NET collaborative study. Eur Respir J. 2013; 42:1604. [PubMed: 23598956]

77. Martín-Casabona N, Bahrmand AR, Bennedsen J, Thomsen VO, Curcio M, Fauville-Dufaux M, et al. Spanish Group for Non-Tuberculosis Mycobacteria. Non-tuberculous mycobacteria: patterns of isolation. A multi-country retrospective survey. Int J Tuberc Lung Dis. 2004; 8:1186. [PubMed: 15527150]

78. van Ingen J, Boeree MJ, de Lange WC, Hoefsloot W, Bendien SA, Magis-Escurra C, et al. Mycobacterium xenopi clinical relevance and determinants, the Netherlands. Emerg Infect Dis. 2008; 14:385. [PubMed: 18325251]

79. Andréjak C, Lescure FX, Pukenyte E, Douadi Y, Yazdanpanah Y, Laurans G, et al. Mycobacterium xenopi pulmonary infections: a multicentric retrospective study of 136 cases in north-east France. Thorax. 2009; 64:291. [PubMed: 19052044]

80. Banks J, Jenkins PA. Combined versus single antituberculosis drugs on the in vitro sensitivity patterns of non-tuberculous mycobacteria. Thorax. 1987; 42:838. [PubMed: 3424264]

81. Watt B. In-vitro sensitivities and treatment of less common mycobacteria. J Antimicrob Chemother. 1997; 39:567. [PubMed: 9184354]

82. Ferro BE, van Ingen J, Wattenberg M, van Soolingen D, Mouton JW. Time-kill kinetics of slowly growing mycobacteria common in pulmonary disease. J Antimicrob Chemother. 2015; 70:2838. [PubMed: 26142475]

83. van Ingen J, van der Laan T, Dekhuijzen R, Boeree M, van Soolingen D. In vitro drug susceptibility of 2275 clinical non-tuberculous mycobacterium isolates of 49 species in The Netherlands. Int J Antimicrob Agents. 2010; 35:169. [PubMed: 20006470]

84. Andréjak C, Almeida DV, Tyagi S, Converse PJ, Ammerman NC, Grosset JH. Improving existing tools for Mycobacterium xenopi treatment: assessment of drug combinations and characterization of mouse models of infection and chemotherapy. J Antimicrob Chemother. 2013; 68:659. [PubMed: 23129730]

85. Varadi RG, Marras TK. Pulmonary Mycobacterium xenopi infection in non-HIV-infected patients: a systematic review. Int J Tuberc Lung Dis. 2009; 13:1210. [PubMed: 19793424]

86. Watt B, Rayner A, Harris G. Comparative activity of azithromycin against clinical isolates of mycobacteria. J Antimicrob Chemother. 1996; 38:539. [PubMed: 8889727]

87. van Ingen J, Boeree MJ, Dekhuijzen PN, van Soolingen D. Clinical relevance of Mycobacterium simiae in pulmonary samples. Eur Respir J. 2008; 31:106. [PubMed: 18166593]

88. Krasnow I, Gross W. Mycobacterium simiae infection in the United States. A case report and discussion of the organism. Am Rev Respir Dis. 1975; 111:357. [PubMed: 1119743]

89. Boisvert H, Truffot C. Relationships between "Mycobacterium simiae" and the "M. aviumintracellulare-scrofulaceum” complex (author's transl). Ann Microbiol (Paris). 1979; 130B:457. [PubMed: 120121]

90. Bell RC, Higuchi JH, Donovan WN, Krasnow I, Johanson WG Jr. Mycobacterium simiae. Clinical features and follow-up of twenty-four patients. Am Rev Respir Dis. 1983; 127:35. [PubMed: 6849546] 
91. Valero G, Peters J, Jorgensen JH, Graybill JR. Clinical isolates of Mycobacterium simiae in San Antonio, Texas. An 11-yr review. Am J Respir Crit Care Med. 1995; 152:1555. [PubMed: 7582293]

92. Valero G, Moreno F, Graybill JR. Activities of clarithromycin, ofloxacin, and clarithromycin plus ethambutol against Mycobacterium simiae in murine model of disseminated infection. Antimicrob Agents Chemother. 1994; 38:2676. [PubMed: 7872769]

93. Jeong SH, Kim SY, Lee H, Ham JS, Hwang KB, Hwang S, et al. Nontuberculous mycobacterial lung disease caused by Mycobacterium simiae: The first reported case in South Korea. Tuberc Respir Dis (Seoul). 2015; 78:432. [PubMed: 26508940]

94. Koh WJ, Stout JE, Yew WW. Advances in the management of pulmonary disease due to Mycobacterium abscessus complex. Int J Tuberc Lung Dis. 2014; 18:1141. [PubMed: 25216826]

95. Pang H, Li G, Wan L, Jiang Y, Liu H, Zhao X, et al. In vitro drug susceptibility of 40 international reference rapidly growing mycobacteria to 20 antimicrobial agents. Int J Clin Exp Med. 2015; 8:15423. [PubMed: 26629031]

96. Broda A, Jebbari H, Beaton K, Mitchell S, Drobniewski F. Comparative drug resistance of Mycobacterium abscessus and M. chelonae isolates from patients with and without cystic fibrosis in the United Kingdom. J Clin Microbiol. 2013; 51:217. [PubMed: 23135941]

97. CaLS. , editor. Institute. Wayne, PA.: CLSI; 2011. Document M100-S11. Performance standards for antimicrobial susceptibility testing. Eleventh informational supplement. ed.

98. Ryu YJ, Koh WJ, Daley CL. Diagnosis and treatment of nontuberculous mycobacterial lung disease: Clinicians' perspectives. Tuberc Respir Dis (Seoul). 2016; 79:74. [PubMed: 27066084]

99. Philley JV, Griffith DE. Management of nontuberculous mycobacterial (NTM) lung disease. Semin Respir Crit Care Med. 2013; 34:135. [PubMed: 23460013]

100. Jeon K, Kwon OJ, Lee NY, Kim BJ, Kook YH, Lee SH, et al. Antibiotic treatment of Mycobacterium abscessus lung disease: a retrospective analysis of 65 patients. Am J Respir Crit Care Med. 2009; 180:896. [PubMed: 19661243]

101. Nash KA, Brown-Elliott BA, Wallace RJ Jr. A novel gene, erm(41), confers inducible macrolide resistance to clinical isolates of Mycobacterium abscessus but is absent from Mycobacterium chelonae. Antimicrob Agents Chemother. 2009; 53:1367. [PubMed: 19171799]

102. Choi GE, Shin SJ, Won CJ, Min KN, Oh T, Hahn MY, et al. Macrolide treatment for Mycobacterium abscessus and Mycobacterium massiliense infection and inducible resistance. Am J Respir Crit Care Med. 2012; 186:917. [PubMed: 22878281]

103. Maurer FP, Castelberg C, Quiblier C, Böttger EC, Somoskövi A. Erm(41)-dependent inducible resistance to azithromycin and clarithromycin in clinical isolates of Mycobacterium abscessus. $\mathrm{J}$ Antimicrob Chemother. 2014; 69:1559. [PubMed: 24500188]

104. Koh WJ, Jeon K, Lee NY, Kim BJ, Kook YH, Lee SH, et al. Clinical significance of differentiation of Mycobacterium massiliense from Mycobacterium abscessus. Am J Respir Crit Care Med. 2011; 183:405. [PubMed: 20833823]

105. Kim HS, Lee KS, Koh WJ, Jeon K, Lee EJ, Kang H, et al. Serial CT findings of Mycobacterium massiliense pulmonary disease compared with Mycobacterium abscessus disease after treatment with antibiotic therapy. Radiology. 2012; 263:260. [PubMed: 22371609]

106. Lyu J, Kim BJ, Kim BJ, Song JW, Choi CM, Oh YM, et al. A shorter treatment duration may be sufficient for patients with Mycobacterium massiliense lung disease than with Mycobacterium abscessus lung disease. Respir Med. 2014; 108:1706. [PubMed: 25245792]

107. Wallace RJ Jr, Brown-Elliott BA, Ward SC, Crist CJ, Mann LB, Wilson RW. Activities of linezolid against rapidly growing mycobacteria. Antimicrob Agents Chemother. 2001; 45:764. [PubMed: 11181357]

108. Jarand J, Levin A, Zhang L, Huitt G, Mitchell JD, Daley CL. Clinical and microbiologic outcomes in patients receiving treatment for Mycobacterium abscessus pulmonary disease. Clin Infect Dis. 2011; 52:565. [PubMed: 21292659]

109. Kasperbauer SH, De Groote MA. The treatment of rapidly growing mycobacterial infections. Clin Chest Med. 2015; 36:67. [PubMed: 25676520]

110. Mitchell JD. Surgical approach to pulmonary nontuberculous mycobacterial infections. Clin Chest Med. 2015; 36:117. [PubMed: 25676524] 
111. Nelson KG, Griffith DE, Brown BA, Wallace RJ Jr. Results of operation in Mycobacterium avium-intracellulare lung disease. Ann Thorac Surg. 1998; 66:325. [PubMed: 9725364]

112. Shiraishi Y, Nakajima Y, Takasuna K, Hanaoka T, Katsuragi N, Konno H. Surgery for Mycobacterium avium complex lung disease in the clarithromycin era. Eur J Cardiothorac Surg. 2002; 21:314. [PubMed: 11825742]

113. Yu JA, Pomerantz M, Bishop A, Weyant MJ, Mitchell JD. Lady Windermere revisited: treatment with thoracoscopic lobectomy/segmentectomy for right middle lobe and lingular bronchiectasis associated with non-tuberculous mycobacterial disease. Eur J Cardiothorac Surg. 2011; 40:671. [PubMed: 21324708]

114. Mitchell JD, Bishop A, Cafaro A, Weyant MJ, Pomerantz M. Anatomic lung resection for nontuberculous mycobacterial disease. Ann Thorac Surg. 2008; 85:1887. [PubMed: 18498789]

115. Watanabe M, Hasegawa N, Ishizaka A, Asakura K, Izumi Y, Eguchi K, et al. Early pulmonary resection for Mycobacterium avium complex lung disease treated with macrolides and quinolones. Ann Thorac Surg. 2006; 81:2026. [PubMed: 16731124]

116. Corpe RF. Surgical management of pulmonary disease due to Mycobacterium aviumintracellulare. Rev Infect Dis. 1981; 3:1064. [PubMed: 7339805]

117. Moran JF, Alexander LG, Staub EW, Young WG Jr, Sealy WC. Long-term results of pulmonary resection for atypical mycobacterial disease. Ann Thorac Surg. 1983; 35:597. [PubMed: 6860003]

118. Shiraishi Y, Katsuragi N, Kita H, Hyogotani A, Saito MH, Shimoda K. Adjuvant surgical treatment of nontuberculous mycobacterial lung disease. Ann Thorac Surg. 2013; 96:287. [PubMed: 23618520]

119. Shiraishi Y, Nakajima Y, Katsuragi N, Kurai M, Takahashi N. Pneumonectomy for nontuberculous mycobacterial infections. Ann Thorac Surg. 2004; 78:399. [PubMed: 15276484]

120. Griffith DE, Girard WM, Wallace RJ Jr. Clinical features of pulmonary disease caused by rapidly growing mycobacteria. An analysis of 154 patients. Am Rev Respir Dis. 1993; 147:1271. [PubMed: 8484642]

121. Andréjak C, Nielsen R, Thomsen VO, Duhaut P, Sørensen HT, Thomsen RW. Chronic respiratory disease, inhaled corticosteroids and risk of non-tuberculous mycobacteriosis. Thorax. 2013; 68:256. [PubMed: 22781123]

122. van Ingen J, Egelund EF, Levin A, Totten SE, Boeree MJ, Mouton JW, et al. The pharmacokinetics and pharmacodynamics of pulmonary Mycobacterium avium complex disease treatment. Am J Respir Crit Care Med. 2012; 186:559. [PubMed: 22744719]

123. Ito Y, Hirai T, Fujita K, Kubo T, Maekawa K, Ichiyama S, et al. The influence of environmental exposure on the response to antimicrobial treatment in pulmonary Mycobacterial avium complex disease. BMC Infect Dis. 2014; 14:522. [PubMed: 25266993]

124. Schulze-Röbbecke R, Buchholtz K. Heat susceptibility of aquatic mycobacteria. Appl Environ Microbiol. 1992; 58:1869. [PubMed: 1622262]

125. Falkinham JO 3rd. Nontuberculous mycobacteria from household plumbing of patients with nontuberculous mycobacteria disease. Emerg Infect Dis. 2011; 17:419. [PubMed: 21392432]

126. Chan, ED., Iseman, MD. Bronchiectasis. In: Broaddus, CEJ.King, TE.Lazarus, SC.Mason, R.Murray, J.Nadel, J., Slutsky, AS., editors. Textbook of Respiratory Medicine. 6th. Elsevier Press; 2014. in press

127. Honda JR, Hess T, Malcolm KC, Ovrutsky AR, Bai X, Irani VR, et al. Pathogenic nontuberculous mycobacteria resist and inactivate cathelicidin: implication of a novel role for polar mycobacterial lipids. PLoS One. 2015; 10:e0126994. [PubMed: 25993058]

128. Kikuchi T, Kobashi Y, Hirano T, Tode N, Santoso A, Tamada T, et al. Mycobacterium avium genotype is associated with the therapeutic response to lung infection. Clin Microbiol Infect. 2014; 20:256. [PubMed: 23829301]

129. Kim SY, Lee ST, Jeong BH, Park HY, Jeon K, Kim JW, et al. Genotyping of Mycobacterium intracellulare isolates and clinical characteristics of lung disease. Int J Tuberc Lung Dis. 2013; 17:669. [PubMed: 23575334] 
Table 1

Relative likelihood that NTM isolated from respiratory tract indicate disease

\begin{tabular}{|l|l|}
\hline Organisms recovered & Relative likelihood of disease \\
\hline M. kansasii & High \\
\hline $\begin{array}{l}\text { MAC, } M . \text { abscessus complex, M. chelonae, M. malmoense, } M . \\
\text { szulgai, } M . \text { xenopi }\end{array}$ & $\begin{array}{l}\text { Intermediate depending on imaging, symptoms, and repeated } \\
\text { isolation; } M \text {. szulgai in certain regions is considered to be more } \\
\text { pathogenic }\end{array}$ \\
\hline M. simiae, M. fortuitum, M. terrae & Low \\
\hline M. gordonae & Very low \\
\hline
\end{tabular}


Table 2

Treatment of Mycobacterium avium complex (MAC)

\begin{tabular}{|c|c|c|c|}
\hline Regimen & Drug & Dose and schedule* & Known adverse effects \\
\hline $\begin{array}{l}\text { Fibrocavitary disease: daily } \\
\text { three drug regimen } \pm \text { thrice } \\
\text { weekly }\end{array}$ & $\begin{array}{l}\text { Azithromycin or } \\
\text { clarithromycin and }\end{array}$ & $\begin{array}{l}250 \mathrm{mg} \text { QD } \\
1000 \mathrm{mg} \text { QD }\end{array}$ & $\begin{array}{l}\text { Diarrhea, hearing loss, metallic taste, QT } \\
\text { prolongation }\end{array}$ \\
\hline \multirow[t]{4}{*}{$\begin{array}{l}\text { aminoglycoside for at least } 12 \\
\text { months of negative sputum } \\
\text { cultures. }\end{array}$} & $\begin{array}{l}\text { Rifampin or rifabutin } \\
\text { and }\end{array}$ & $\begin{array}{l}10 \mathrm{mg} / \mathrm{kg} \mathrm{QD} \\
\text { (maximum } 600 \mathrm{mg} \text { ) or } 150-300 \mathrm{mg} \\
\mathrm{QD}\end{array}$ & $\begin{array}{l}\text { Hepatitis, drug-drug interactions, fever, } \\
\text { chills, arthralgias, thrombocytopenia, } \\
\text { leukopenia, acute hemolytic anemia, } \\
\text { uveitis, decreases clarithromycin levels }\end{array}$ \\
\hline & Ethambutol & $\begin{array}{l}15 \mathrm{mg} / \mathrm{kg} \mathrm{QD} \\
\text { (max 2.4 grams) }\end{array}$ & $\begin{array}{l}\text { Optic neuritis (color blindness, scotoma, } \\
\text { decreased visual acuity and/or visual } \\
\text { defect), hepatitis }\end{array}$ \\
\hline & $\begin{array}{l} \pm \text { Amikacin or } \\
\text { streptomycin }\end{array}$ & $\begin{array}{l}10-25 \mathrm{mg} / \mathrm{kg}^{* * *} \mathrm{IV} \text { or IM TIW for } \\
\text { the first } 2-3 \text { months }\end{array}$ & $\begin{array}{l}\text { Renal failure, cranial VII (vestibular and } \\
\text { cochlear) toxicity, hypomagnesemia }\end{array}$ \\
\hline & $\begin{array}{l}\text { Clofazimine (for } \\
\text { intolerance to } \\
\text { rifamycins) }\end{array}$ & $100-300 \mathrm{mg}$ QD & $\begin{array}{l}\text { GI intolerance (abdominal pain, nausea, } \\
\text { vomiting, diarrhea -occurring in } 40- \\
50 \% \text { ), skin discoloration, QT } \\
\text { prolongation }\end{array}$ \\
\hline \multirow{3}{*}{$\begin{array}{l}\text { Nodular-bronchiectasis: thrice } \\
\text { weekly for at least } 12 \text { months } \\
\text { of negative sputum cultures. }\end{array}$} & $\begin{array}{l}\text { Azithromycin or } \\
\text { clarithromycin and }\end{array}$ & $\begin{array}{l}500 \mathrm{mg} \text { TIW } \\
1000 \mathrm{mg} \text { TIW }\end{array}$ & See above \\
\hline & $\begin{array}{l}\text { Rifampin or rifabutin* } \\
\text { and }\end{array}$ & $\begin{array}{l}600 \mathrm{mg} \text { TIW } \\
150-300 \mathrm{mg} \text { TIW }\end{array}$ & See above \\
\hline & Ethambutol & 25 mg/kg TIW & See above \\
\hline
\end{tabular}

Key References: $(29,45,57)$

* Unless indicated, all dosages are given orally.

** Reserve rifabutin for advanced or previously treated disease. Rifabutin levels may be increased by macrolides. Hematologic complications is more common with rifabutin than rifampin.

****

Some centers favor lower doses for better tolerability. Monitor peak aminoglycoside level weekly.

$\mathrm{IV}=$ intravenous; $\mathrm{IM}=$ intramuscular; $\mathrm{QD}=$ once daily, TIW = thrice weekly 
Table 3

Treament of Mycobacterium kansasii

\begin{tabular}{|l|l|l|l|}
\hline Regimen & Drug & Dose and schedule & Known adverse effects \\
\hline Daily for 12 months of negative cultures & Isoniazid *and & $300 \mathrm{mg}$ QD & $\begin{array}{l}\text { Hepatotoxicity, peripheral neuropathy, } \\
\text { drug-induced lupus, agranulocytosis }\end{array}$ \\
& $\begin{array}{l}\text { Rifampin and } \\
\text { Ethambutol }\end{array}$ & $\begin{array}{l}600 \mathrm{mg} \text { QD } \\
15 \mathrm{mg} / \mathrm{kg} \text { QD } \\
\text { (max 2.4 grams) } \\
\end{array}$ & $\begin{array}{l}\text { See above } \\
\text { See above }\end{array}$ \\
& $\begin{array}{l}\text { Azithromycin or clarithromycin } \\
\text { may be substituted for isoniazid }\end{array}$ & $1000 \mathrm{mg} \mathrm{mD}$ & See above \\
\hline
\end{tabular}

Key References: $(29,45)$

* Consider adding pyridoxime $20 \mathrm{mg}$ QD to lower risk of INH-induced peripheral neuropathy 
Table 4

Treament of Mycobacterium malmoense

\begin{tabular}{|l|l|l|l|}
\hline Regimen & Drug & Dose and schedule & Known adverse effects \\
\hline $\begin{array}{l}\text { Daily therapy for at least 12 months of } \\
\text { negative sputum cultures }\end{array}$ & $\begin{array}{l}\text { * Clarithromycin or } \\
\text { azithromycin and } \\
\text { Rifampin and }\end{array}$ & $1000 \mathrm{mg}$ QD or 250 mg QD & See above \\
& $\begin{array}{l}\text { Ethambutol } \\
\text { Moxifloxacin in place of } \\
\text { the macrolide }\end{array}$ & $\begin{array}{l}600 \mathrm{mg} \text { QD } \\
15 \mathrm{mg} / \mathrm{kg} \text { QD }\end{array}$ & $\begin{array}{l}\text { See above } \\
\text { See above } \\
\text { Tendonitis, QT prolongation, } \\
\text { photosensitivity }\end{array}$ \\
\hline
\end{tabular}

Key References: $(45,69)$

Fluoroquinolones may be used as an alternative in those intolerant to macrolides 
Table 5

Treatment of Mycobacterium szulgai

\begin{tabular}{|l|l|l|l|}
\hline Regimen & Drug & Dose and schedule & Known adverse effects \\
\hline $\begin{array}{l}\text { No proven regimen. Daily therapy for > 12 months of } \\
\text { negative cultures. }\end{array}$ & Clarithromycin and & $1000 \mathrm{mg}$ QD & See above \\
& Rifampin and & $10 \mathrm{mg} / \mathrm{kg}$ QD (max $600 \mathrm{mg})$ & See above \\
& Ethambutol and & $15 \mathrm{mg} / \mathrm{kg}$ QD (max 2.4 gram) & See above \\
& \pm Ciprofloxacin & $250-750 \mathrm{mg}$ BID & See moxifloxacin above \\
\hline
\end{tabular}

Key References: $(73,74)$ 
Table 6

Treatment of Mycobacterium xenopi

\begin{tabular}{|l|l|l|l|}
\hline Regimen & Drug & Dose and schedule & Known adverse effects \\
\hline $\begin{array}{l}\text { No proven regimen. Daily therapy for }>12 \\
\text { months of negative cultures. }\end{array}$ & Clarithromycin and & $1000 \mathrm{mg}$ QD & See above \\
& Rifampin and & $10 \mathrm{mg} / \mathrm{kg}$ QD (max $600 \mathrm{mg})$ & See above \\
& Ethambutol & $15 \mathrm{mg} / \mathrm{kg}$ QD (max 2.4 grams) & See above \\
& \pm Moxifloxacin & $400 \mathrm{mg}$ QD & See above \\
& \pm amikacin* & $10-25 \mathrm{mg} / \mathrm{kg}$ IV or IM TIW for the first & See above \\
\hline
\end{tabular}

Key References: $(26,45)$

Based on an in vivo murine study (84) 
Table 7

Treatment of Mycobacterium simiae

\begin{tabular}{|c|c|c|c|}
\hline Regimen & Drug & Dose and schedule & Known adverse effects \\
\hline $\begin{array}{l}\text { No proven regimen. Relationship of in } \\
\text { vitro susceptibility and clinical outcome } \\
\text { is not clear. }\end{array}$ & $\begin{array}{l}\text { Clarithromycin and } \\
\text { Rifampin and } \\
\text { Ethambutol } \\
\pm \text { Moxifloxacin } \\
\pm \text { Trimethoprim-sulfamethoxazole }\end{array}$ & $\begin{array}{l}1000 \mathrm{mg} \text { QD } \\
10 \mathrm{mg} / \mathrm{kg} \text { QD }(\max 600 \\
\mathrm{mg}) \\
15 \mathrm{mg} / \mathrm{kg} \text { QD }(\max 2.4 \\
\text { grams) } \\
400 \mathrm{mg} \text { QD } \\
\text { One double-strength tablet } \\
\text { BID }\end{array}$ & $\begin{array}{l}\text { See above } \\
\text { See above } \\
\text { See above } \\
\text { See above } \\
\text { Hypersensitivity, rash, } \\
\text { myelosuppression, } \\
\text { interstitial nephritis, } \\
\text { increased liver function tests }\end{array}$ \\
\hline
\end{tabular}

Key References: (29) 


\section{Table 8}

Treatment of Mycobacterium abscessus complex

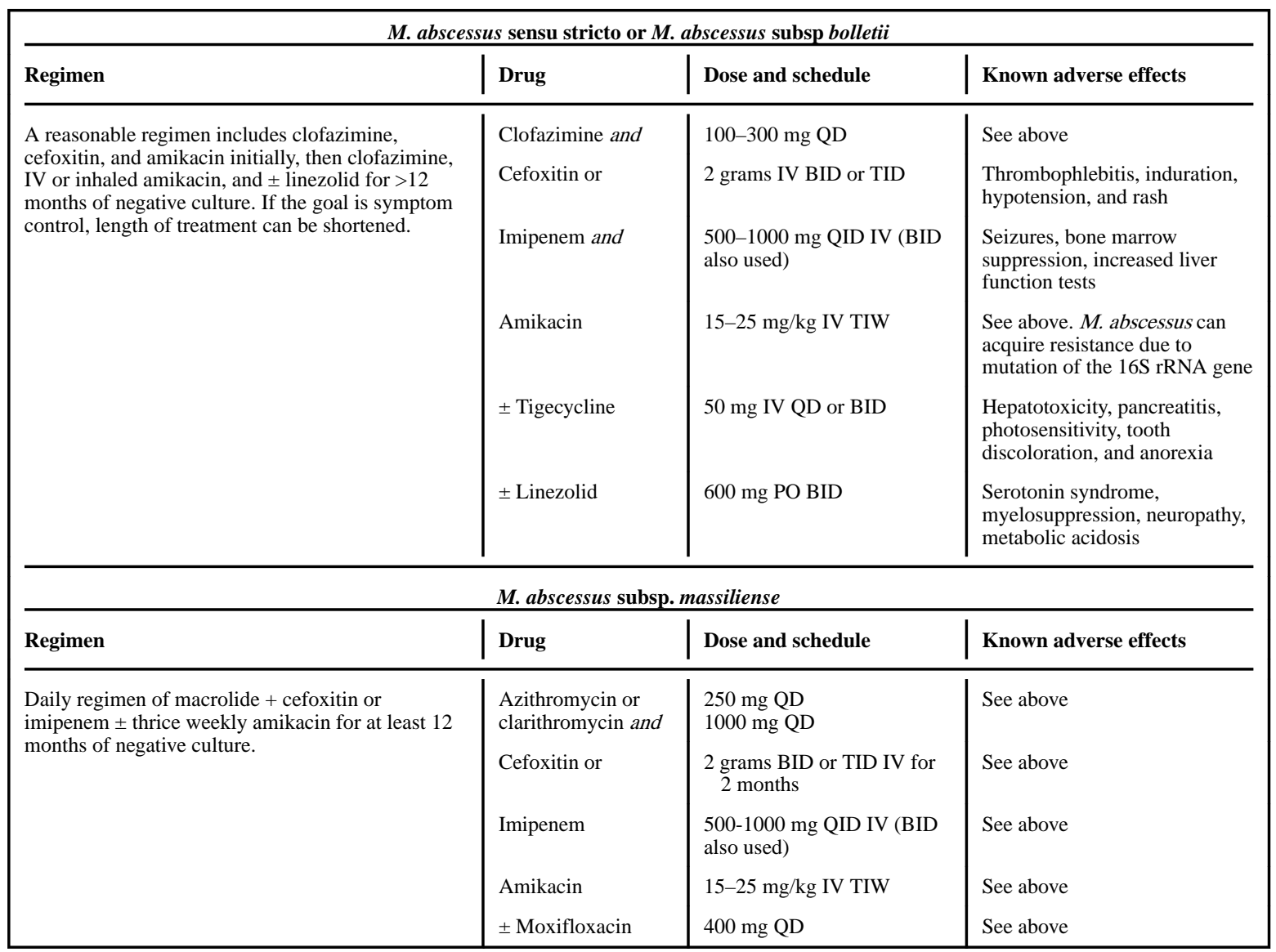

Key References: $(29,45,107)$ 


\section{Table 9}

\section{Measures to maximize favorable treatment outcome}

\begin{tabular}{|c|c|}
\hline Measures & Key references \\
\hline Test NTM for resistance to macrolide and possibly the aminoglycosides & $(27,34,35,41)$ \\
\hline $\begin{array}{l}\text { Use at least a three-drug regimen of azithromycin, rifampin, and ethambutol for MAC-LD, thrice weekly for non-cavitary } \\
\text { minimal disease and daily for cavitary and more severe disease }\end{array}$ & $(29,42-44)$ \\
\hline $\begin{array}{l}\text { If rifampin is used with macrolides, the dose of macrolides may need to be increased and preferably, macrolide levels } \\
\text { checked }\end{array}$ & $(34,45,122)$ \\
\hline Consider including intravenous or inhaled amikacin for those with more severe or cavitary disease & $(27,47,48)$ \\
\hline Take measures to avoid re-exposure such as avoidance of aerosolized soil and water & (123) \\
\hline Consider increasing hot water heater temperature to $130^{\circ} \mathrm{F}$ & $(124,125)$ \\
\hline Airway clearance mechanisms for bronchiectasis (e.g., Acapella ${ }^{\circledR}$ valve, Aerobika ${ }^{\circledR}$, TheraVest $^{\circledR}$, hypertonic saline) & (126) \\
\hline Surgical lung resection for severe but localized disease in selected patients & $(29,110)$ \\
\hline
\end{tabular}

Curr Treat Options Infect Dis. Author manuscript; available in PMC 2017 December 01. 